\title{
Investigation of foot-and-mouth disease outbreaks in the Mbala and Kazungula districts of Zambia
}

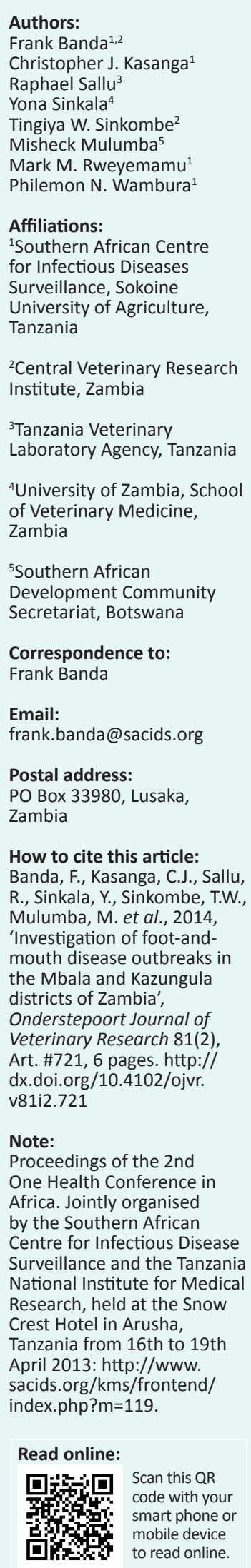

Foot-and-mouth disease (FMD) is an acute, highly contagious viral infection of domestic and wild cloven-hoofed animals. It is known to be endemic in Zambia, with periodic outbreaks occurring in different geographical areas of the country. This study was conducted to investigate the presence of FMD virus (FMDV) in reported FMD-suspected cases in cattle from the Kazungula and Mbala districts of Zambia. Sixty epithelial tissues or oesophagealpharyngeal (OP) scrapings (probang samples) were collected from Mbala $(n=51)$ and Kazungula $(n=9)$ and examined for FMDV. The FMDV viral RNA and serotypes were examined by realtime reverse transcription polymerase chain reaction (qRT-PCR) and antigen Enzyme- linked immunosorbent assay (ELISA), respectively. Twenty-two samples (36.7\%) were positive for the FMDV genome by qRT-PCR with Cycle threshold $(\mathrm{Ct})$ values ranging from 13 to 31. The FMDV-positive samples from epithelial tissues showed relatively higher $\mathrm{Ct}$ values compared to those obtained from OP scrapings, irrespective of geographical location. Forty percent $(40 \% ; n=4)$ of epithelial tissues from Mbala were serotyped into SAT 2 serotype by antigen ELISA. Kazungula samples were serotyped into SAT 1. These findings indicated that Mbala and Kazungula districts had FMD outbreaks in 2012 that were ascribed to at least FMDV serotype SAT 2 and SAT 1 field strains. Furthermore, regular interaction between buffalos from the Mosi-o Tunya Park and domestic animals from surrounding areas could contribute to the occurrence of regular FMD outbreaks in Kazungula, whilst the uncontrolled animal movements across borders between Mbala and Nsumbawanga could be responsible for disease outbreaks in Mbala. In-depth molecular biological studies, including sequencing and phylogeny of the viruses, should be conducted to elucidate the complex epidemiology of FMD in Zambia, thereby providing valuable information needed for the rational control strategy of FMD in Zambia and neighbouring countries.

\section{Introduction}

Foot-and-mouth disease (FMD) is the most contagious disease of mammals and has a great potential for causing severe economic loss in susceptible cloven-hoofed animals (OIE Terrestrial Manual 2010). It is one of the most economically important infectious diseases of livestock as it can severely constrain international trade of animals and animal products (Li-na et al. 2011). The agent of the disease, FMD virus (FMDV) is a single-stranded, positive-sense RNA virus in the genus aphthovirus, family Picornaviridae. There are seven immunologically-distinct serotypes of the virus, namely: types O, A, C, Asia 1 and the South African serotypes SAT 1, SAT 2 and SAT 3. Infection with one serotype does not confer immunity against another (Ferris et al. 2006). This needs to be taken into consideration when developing intervention strategies in endemic settings; it is important to take into account the characteristics of the different serotypes in different ecological systems (Loth et al. 2011). Further collection and analysis of samples, together with improved local epidemiological investigation into FMD outbreaks in countries in Sub-Saharan Africa, is required to improve our understanding of the complex epidemiology of FMD in the region.

Foot-and-mouth disease is endemic in Africa and the epidemiology of the disease is more complicated than in other parts of the world (Vosloo et al. 2006), as six of the seven serotypes (O, A, C, SAT 1, SAT 2 and SAT 3) have occurred in Africa (Rweyemamu et al. 2008; Vosloo et al. 2002). In addition to having endemic infection by six of the seven serotypes of FMDV, serotype distribution differs between regions and intratypic variants within serotypes occur (Vosloo et al. 2002). In Southern Africa, SAT 1, SAT 2 and SAT 3 serotypes of FMDV are maintained by large numbers of African buffaloes (syncerus caffer), which provide a potential source of infection to domestic livestock and wild animals (Vosloo \& Thomson 2004; Thomson et al. 2003).

In Zambia, FMD is endemic and the first outbreak was reported in 1933 (Overby \& Zyambo 1983; Perry \& Hedger 1984), but its epidemiology is still unknown. Data available indicate that 
there are three high-risk areas identified where FMD has occurred repeatedly (Figure 1). Rampant outbreaks of FMD are still observed in Zambia (Ministry of Livestock and Fisheries Development (MLFD) 2010; Knowles 2010) with the recent ones occurring in January and May 2012 in the Mbala and Kazungula districts, respectively. The genotypes of circulating FMDV serotypes in Zambia have not been studied. Furthermore, the occurrence and distribution pattern of the known serotypes in the country are not fully exploited and hence, poorly understood (Mulenga, pers. comm., 2012).

In this study, a panel of virological-detection assays, including Antigen enzyme-linked immunosorbent assay (ELISA) and RNA extraction followed by one-step real time reverse transcription-polymerase chain reaction (qRT-PCR), were used. This was done in order to determine the presence of the FMD viral genome and typing for the FMDV serotype responsible for the FMD outbreaks in Mbala and Kazungula districts of Zambia.

\section{Materials and methods \\ Study area}

The FMD outbreaks in cattle were suspected in January 2012 in the Mbala district in the Northern Province and in May 2012 in the Kazungula district in the Southern Province of Zambia (Figure 2 and Figure 3). The Mbala district is bordered with the Nsumbawanga region of Tanzania, whilst the Kazungula district is in the Zambezi basin. In both areas, there is subsistence-type of farming practice. The Mbala district has a livestock population of 21 560, whilst the Kazungula district has 65 125. In the Kazungula distict there is greater possibility of interaction between livestock and wildlife, as most of it is in a game management area (GMA). In the Mbala district there is less chance of interaction between the two because the nearest game park, Katavi National Park, is approximately $600 \mathrm{~km}$ away on the Tanzanian side; there are, however, reports of interaction of livestock in the border areas.

\section{Sample collection}

Epithelial tissues and probang samples were collected from FMD-suspected animals. All of the 60 (100\%) samples examined were from bovine species. Of these, 47 (78.33\%) were probang tissue samples, whilst 13 (21.66\%) were epithelial tissues (three mouth tissues and 10 foot tissues). Samples were collected in duplicate from Mbala $(n=51)$ and Kazungula $(n=9)$. Areas where the samples were collected are shown in (Figure 2 and Figure 3). Seventeen (17) of the 51 samples collected from Mbala came from Itokoto, which is an area with no active cases, but is in close proximity to the outbreak area. The tissue specimens were collected as described by Kitching and Donaldson (1987) and the probang samples were taken as described in the OIE Terrestrial Manual (2010). The epithelial tissues were transported

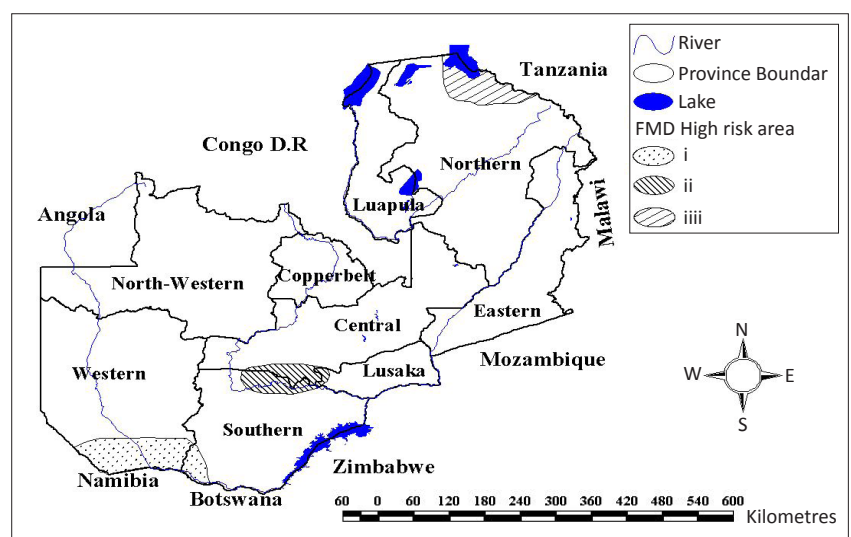

Source: Mweene et al. (1996)

FIGURE 1: Map of Zambia showing the provinces and the areas at risk of footand-mouth disease.

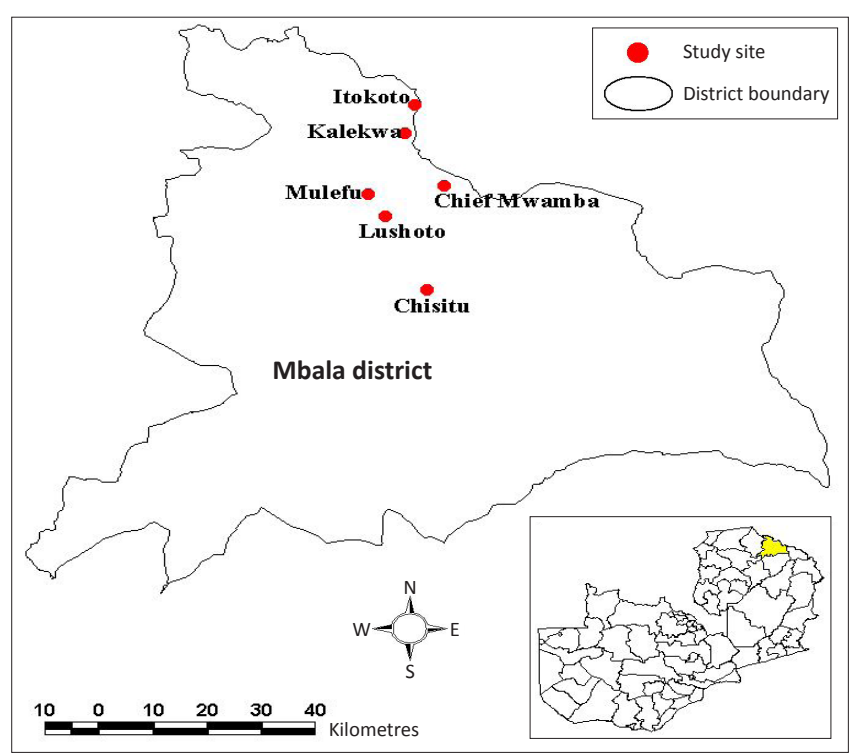

Source: Tsetse control unit of the department of veterinary services, Chilanga, Zambia FIGURE 2: Map showing the study area and the sampling sites in Mbala district of the northern province of Zambia.

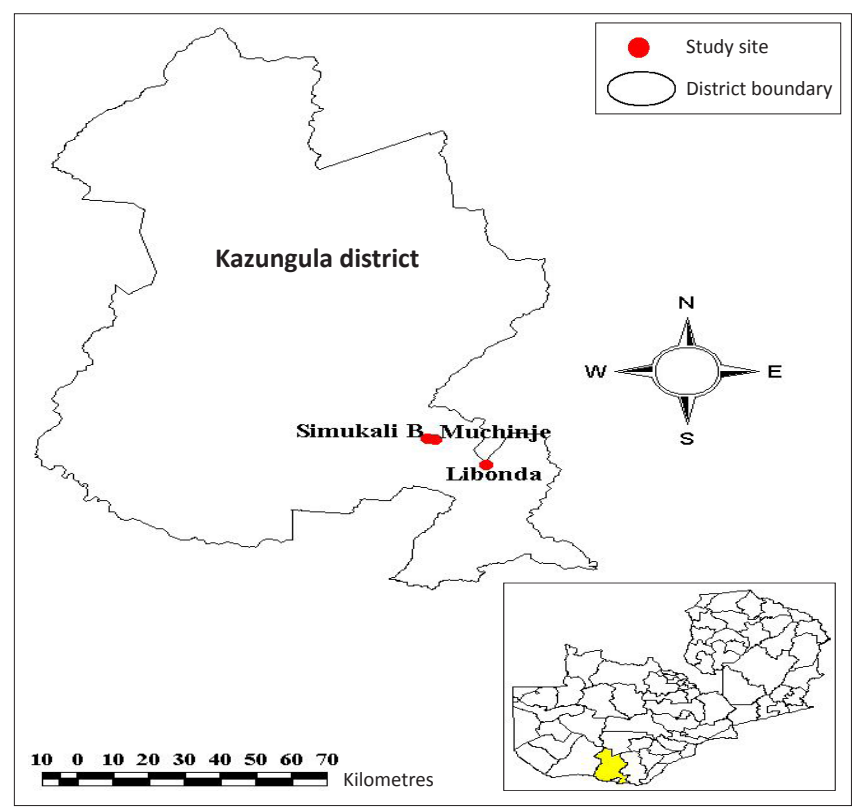

Source: Tsetse control unit of the department of veterinary services, Chilanga, Zambia

FIGURE 3: Map showing the study area and the sampling sites in Kazungula district of the southern province of Zambia. 
from the collection site to the diagnostic laboratory in $0.04 \mathrm{M}$ phosphate buffer ( $\mathrm{pH} 7.2$ - $\mathrm{pH} 7.6$ ) with $50 \%$ glycerol at $4{ }^{\circ} \mathrm{C}$. The probang samples were placed in transport fluid (composed of $0.08 \mathrm{M}$ phosphate buffer containing $0.010 \%$ bovine serum albumin, $0.002 \%$ phenol red and antibiotics) and adjusted to pH 7.2 (OIE Terrestrial Manual 2010). All specimens were packaged as described elsewhere (Kitching \& Donaldson 1987) and shipped to the Tanzania Veterinary Laboratory Agency (TVLA); copies were also submitted to the regional reference laboratory of the Botswana Vaccine Institute (BVI).

\section{Virus isolation and typing}

Epithelium samples were ground in phosphate buffered saline (PBS) using sand and a pestle and mortar to give a $10 \%$ suspension. These suspensions were tested in an antigendetection ELISA (Roeder \& Le Blanc Smith 1987) both at TVLA and BVI. Total RNA was extracted from the ground tissue suspension and the oesophageal-pharyngeal (OP) samples using QIAamp Viral RNA kit (QIAGEN, Germany) following manufacturer's instructions. To determine the presence of FMD viral RNA, samples were also tested by one-step qRT-PCRs targeting the $3 \mathrm{D}$ regions of the FMDV genome (Callahan et al. 2002) using an Agpath-ID One-step qRT-PCR kit (Applied Biosystems, USA) (P/N AM1005, 4387424, 4388519) according to manufactures instructions. A 7500 fast real-time PCR system machine (Applied Biosystems, USA) was used. At BVI, virus isolation was performed on two samples submitted; there was no virus isolated on the first and second passage. PCR, followed by sequencing, was performed later.

\section{Results}

Out of a total of 257 cattle that were physically examined in both areas, 33 (12.8\%) animals showed clinical signs and lesions suggestive of FMD. The principal clinical signs were salivation and lameness. Mouth lesions consisted of erosions and ulcers, which were mainly on the tongue and dental pad. Foot lesions comprised of erosions on the interdigital spaces and the coronary bands. On the latter, the lesions were so severe that the hoof tended to separate from the coronary band. The most-affected cattle showed foot lesions and, in most cases, healing mouth lesions where observed. No deaths were recorded during the outbreak in both districts.

Using a positive cut-off cycle threshold (Ct) value of 32.0 (Shaw et al. 2007), 22 (36.7\%) samples were positive for FMDV genome by qRT-PCR (Figure 4), with Ct values ranging from 13 to 31. After repeat testing, 38 (63.3\%) samples still showed $\mathrm{Ct}$ values of 'No Ct'; hence, they were considered to be no virus detected (NVD) and where excluded from further study. All the $13(100 \%)$ of the epithelial tissues examined came out positive. The lowest $\mathrm{Ct}$ value of 13 was recorded from a sample from the Kazungula district, whilst the highest was a sample examined from the Mbala district, with a $\mathrm{Ct}$ value of 30. No virus was detected in all 17 samples collected from the Itokoto village, an area with no active cases of FMD. In general, samples collected from the Kazungula district showed lower $\mathrm{Ct}$ values than those collected from the Mbala district. The $\mathrm{Ct}$ values ranged between 13 and 18, indicating higher levels of viral RNA in the samples collected from the Kazungula district than those collected from the Mbala district (Table 1). Lower Ct values were observed for most epithelial tissues than those from the probang tissues, indicating that there were higher levels of viral RNA in the epithelial tissues than in the OP samples.

At TVLA, four of the 13 epithelial samples from Mbala demonstrated FMDV SAT 2 antigens by ELISA. At BVI, FMDV SAT 1 was demonstrated from the Kazungula samples and FMDV SAT 2 from the Mbala samples. History of previous vaccinations with serotype $\mathrm{O}$ in some areas was recorded in the Mbala district, whilst in the Kazungula district there was no history of vaccinations against FMDV.

\section{Discussion}

Longjam et al. (2011) stated that for effective control of FMD, outbreaks should be detected at an early stage and persistent infections should be recognised to prevent further transmittance. The observation of high $\mathrm{Ct}$ values from samples in both outbreaks and clinical signs of FMD, coupled with the confirmation of SAT 2 from the Mbala samples and SAT 1 from the Kazungula samples at both TVLA and BVI, confirmed that the majority of the animals in these herds had been infected by FMDV. Due to the foot lesions characteristic of FMD, some animals were observed as having difficulties in moving; Hunter (1997) also observed this.

Using a positive cut-off Ct value of 32.0 (Shaw et al. 2007), it was noted that only eight of the $47(17.02 \%)$ probang samples examined had $\mathrm{Ct}$ values below 32.0. This is contrary to the epithelial tissues, which showed a $100 \%$ positivity rate. It must be noted that the FMDV genome-positive samples from the epithelial tissues showed relatively higher $\mathrm{Ct}$ values compared to those obtained from the OP scraping; this was

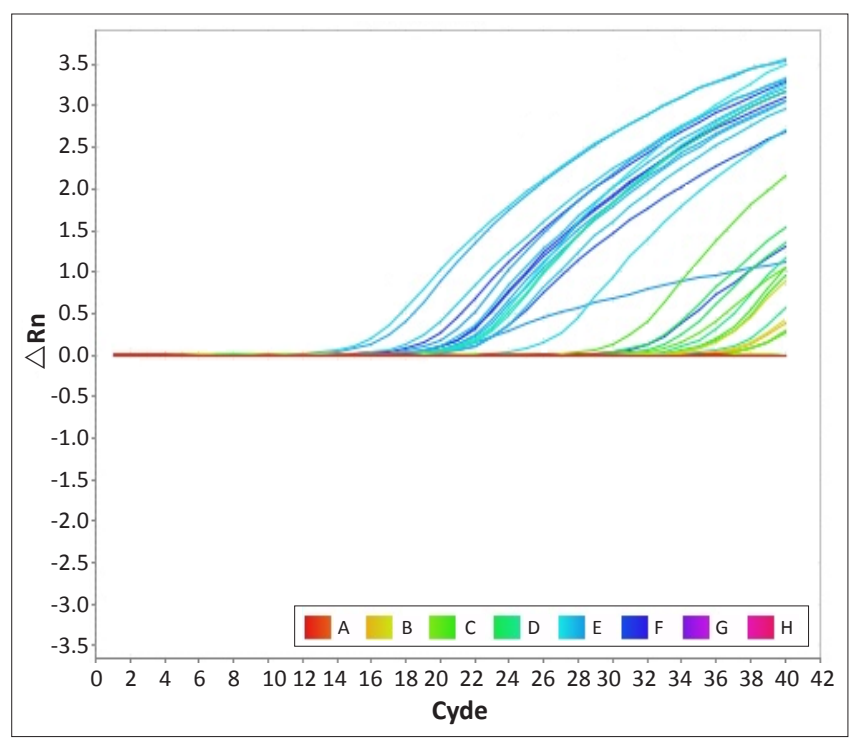

Source: Applied Biosystems 7500 software

FIGURE 4: Graph showing amplification plot for one step real-time polymerase chain reaction. 
TABLE 1: Description of samples that were used in this study detailing real time reverse transcriptance polymerase chain reaction and antigen ELISA results.

\begin{tabular}{|c|c|c|c|c|c|}
\hline Sample ID & Location & Vaccination status & Sample type & qRT-PCR-Ct(3D) & Ag-ELISA result \\
\hline 10 & Itokoto & Vaccinated & Probang & 36 & Negative \\
\hline 16 & Kalekwa & Vaccinated & Probang & 34 & Negative \\
\hline 17 & Kalekwa & Vaccinated & Probang & 36 & Negative \\
\hline 22 & Kalekwa & Vaccinated & Probang & 36 & Negative \\
\hline 25 & Kalekwa & Vaccinated & Probang & 36 & Negative \\
\hline 26 & Kalekwa & Vaccinated & Probang & 31 & Negative \\
\hline 28 & Kalekwa & Vaccinated & Probang & 28 & Negative \\
\hline 29 & Kalekwa & Vaccinated & Probang & 36 & Negative \\
\hline 30 & Kalekwa & Vaccinated & Probang & 33 & Negative \\
\hline 31 & Kaka & Not Vaccinated & Probang & 34 & Negative \\
\hline 33 & Kaka & Not Vaccinated & Probang & 30 & Negative \\
\hline 34 & Kaka & Not Vaccinated & Probang & 31 & Negative \\
\hline 40 & Kaka & Not Vaccinated & Probang & 32 & Negative \\
\hline 41 & Simango & Not Vaccinated & Probang & 35 & Negative \\
\hline 44 & Simango & Not Vaccinated & Probang & 19 & Negative \\
\hline 45 & Simango & Not Vaccinated & Probang & 20 & Negative \\
\hline 46 & Simukali & Not Vaccinated & Probang & 24 & Negative \\
\hline 47 & Libonda & Not Vaccinated & Epithelium & 13 & Negative \\
\hline 48 & Simukali & Not Vaccinated & Epithelium & 16 & Negative \\
\hline 49 & Mwamba & Vaccinated & Epithelium & 20 & Negative \\
\hline 50 & Mulifu & Vaccinated & Epithelium & 18 & Negative \\
\hline 51 & Mulifu & Vaccinated & Epithelium & 19 & Negative \\
\hline 52 & Mulifu & Not Vaccinated & Epithelium & 19 & SAT 2 \\
\hline 53 & Mulifu & Not Vaccinated & Epithelium & 14 & SAT 2 \\
\hline 54 & Mulifu & Not Vaccinated & Epithelium & 17 & Negative \\
\hline 55 & Lushoto & Not Vaccinated & Epithelium & 19 & SAT 2 \\
\hline 56 & Lushoto & Not Vaccinated & Epithelium & 20 & Negative \\
\hline 57 & Lushoto & Not Vaccinated & Epithelium & 30 & Negative \\
\hline 60 & Simango & Not Vaccinated & Epithelium & 18 & Negative \\
\hline
\end{tabular}

ID, identity; Ct, Cycle threshold; qRT-PCR, real-time reverse transcription polymerase chain reaction; Ag-ELISA, antigen ELISA; ELISA, enzyme-linked immunosorbent assay

irrespective of geographical location. This could be attributed to the fact that there was much higher replication of the virus in the epithelial tissues compared to the OP samples; hence, more viral RNA was recovered from the epithelial cells than the OP cells. This could also be because epithelial tissues were from active clinical cases, whilst OP samples were from those recovering or from non-clinical cases. The one-step qRT-PCR generally showed much higher $\mathrm{Ct}$ values for the Kazungula samples than for the Mbala samples (Table 1). One of the contributing factors to this difference could be that different serotypes of FMDV could be responsible for the outbreaks in the two regions. Furthermore, samples from Mbala were collected in January 2012 and were subjected to longer storage time before being finally tested, as compared to the ones from Kazungula, which were only stored for two weeks before being examined. The storage facilities at Central Veterinary Research Institute (CVRI) were also questionable in terms of maintaining the cold chain due to frequent power cuts. Since samples were transported from Zambia to Tanzania by road, the maintenance of cold chain was also questionable, despite the fact that dry ice was used, as it took almost $36 \mathrm{~h}$ for samples to arrive at the laboratory. These facts were also found to be true by Mwiine et al. (2009), who reported that the low rate of virus, despite healing lesions suggestive of FMDV, was probably due to long transportation times for samples and difficulties in maintaining the cold chain during both transportation and storage. It is worthwhile to note also that all the OP samples collected in the areas with no active cases of FMD were deemed to be no virus detected (NVD) by one-step qRT-PCR. This was a good negative control for the study and also showed the extent of the outbreaks.

During the investigation of the outbreak in the Kazungula district, a discussion with local people and wildlife officials in the area revealed that each year during the rainy season a herd of buffalo moves up into areas where there is human habitation and, at times, mingles with local herds of cattle. These buffalo, however, return to the game park after the rainy season. The fence that was in the Kazungula district and was meant to separate wildlife and domestic animals has since been vandalised and is no longer standing. This leads to free interaction of cattle and wildlife from the nearby Mosi-o Tunya National Park. In this outbreak, however, no buffalo were observed interacting with cattle. Furthermore, vaccinations where not conducted in some camps within the district. It is known that buffalo are important for their role in maintaining FMD infection and their ability of infecting other susceptible species in Sub-Saharan Africa (Thomson \& Bastos 2004; Thomson et al. 2003). They have been shown to be the source of infection for impala and domestic animals 
in proximity of the Kruger National Park (KNP) and other game parks in southern Africa (Thomson \& Bastos 2004).

In the Mbala district, previous outbreaks of FMD have been believed to be extensions of outbreaks in the Sumbawanga district of Tanzania, which borders the Mbala district of Zambia (Overby \& Zyambo 1983; J. Banda, pers. comm., 2012). Despite the fact that there is no game park with herds of buffalo in the Mbala district, Katavi National Park in the Sumbawanga region of Tanzania is known to house a number of buffalo and these could be speculated to be the sources of the FMD outbreaks in this region. Furthermore, during the outbreak investigation, a discussion with the local people revealed that, fortnightly, there are organised local markets (commonly known as Munanda) in the Sumbawanga district and at these markets cattle fetch a much lower price compared to the price of cattle in Zambia. Villagers also revealed that cattle traders usually pass by the villages on their way home from these markets with their animals and at times ask for shelter to rest for a night or two. During this time, the traders' animals interact with the local animals. Intermarriages are also common on the borders and cattle are usually used for payment of the bride. This entails movement of animals from one family to another. In addition, pockets of farmers deliberately do not vaccinate their animals. The SAT 2 FMDV outbreaks in Mbala could be extensions from Tanzania, which has previously reported high incidences of FMD outbreaks along the borders (Picado et al. 2010). However, it should also be noted that there is a possibility of having more FMDV serotypes circulating in the area and that they could not be detected during this study. Previous reports (Knowles 2010) have indicated outbreaks of FMDV SAT 1 in 2009 and FMDV serotype $O$ in 2010 in the same areas.

\section{Conclusion and recommendations}

This study has detected the FMDV genome in the samples collected from both the Mbala and Kazungula districts. Furthermore, four $(40 \%)$ out of the total of 10 epithelial samples examined from the Mbala district using antigen ELISA at TVLA, showed high prevalence of antigens to FMDV serotypes SAT 2; this was also confirmed by results obtained from BVI. The study also detected FMDV SAT1 antigens from the Kazungula samples. It can thus be concluded that Zambia had FMD outbreaks in both the Kazungula and Mbala districts in 2012. Vosloo et al. (2003) stated that current outbreaks of FMD should be researched in order to ensure that vaccine strains could be appropriately matched against the strains currently in the field. It was with this background that this study was conducted.

This study could not conclude the sources of these outbreaks, although information on the ground indicated that they could be from buffalo in the Kazungula district. This would be due to the regular interaction between buffalo from the Mosi-o Tunya National Park and the domestic animals from the surrounding areas. Cross-border movements of animals between the Mbala district and the Sumbawanga region also play a major role in the FMD outbreaks in these areas. Thus, there is a need to conduct a phylogenetic analysis of the SAT2 outbreak in the Mbala district in order to infer the genetic relationship of viruses circulating in the two regions.

It is also recommended that cattle owners who take their livestock to graze in national parks should be sensitised on the potential risk of transmission of FMDV from cattle to wildlife. Restriction of animal movement must be enforced to minimise further trans-boundary transmission of the disease. This could be done by erecting cordon lines, setting up more veterinary camps and increasing the number of veterinary assistants (VA) in FMD high-risk areas, as the areas are too vast for the number of VAs currently manning them.

Because of the porous borders, a regional FMD control strategy should be developed. Furthermore, animal identification and the monitoring of animal movements are necessary to identify the cross-border movements and market chain interactions of ruminants; this would lead to improved border and movement controls. Stricter adherence to protocols for the issuance of movement permits should also be followed.

It also recommended that in order to characterise the circulating FMDV serotypes, more systematic epidemiological and molecular studies be carried out. These studies should be done not only in cattle but also in small ruminants and buffalo to ascertain their roles in the regular FMD outbreaks in Zambia. Therefore, for Zambia to properly control FMD there is a need to invest in scientifically valid epidemiological investigations in order to help devise a national strategic plan. This would include re-evaluation of the vaccines used and the role of wildlife animals in the transmission and maintenance of FMD.

\section{Acknowledgements}

This study was supported by the Southern Africa Centre for Infectious Disease Surveillance (SACIDS) and the SADCTADS project in Zambia. The authors would like to thank George Thobokwe for virus isolation and typing and Milner Mukubwali for digitising maps of the Kazungula and Mbala districts. This work was supported by the Wellcome Trust Grant WT087546MA to the Southern African Centre for Infectious Diseases \& Surveillance (SACIDS).

\section{Competing interests}

The authors declare that they have no financial or personal relationship(s) that may have inappropriately influenced them in writing this article.

\section{Authors' contributions}

F.B. (Sokoine University of Agriculture and Central Veterinary Research Institute, Zambia) prepared the manuscript, collected samples, performed most of the experiments and edited the manuscript. C.J.K. (Sokoine University of Agriculture) undertook the experimental design and edited the manuscript. R.S. (Tanzania Veterinary Laboratory Agency) performed some laboratory work. Y.S. 
(University of Zambia) collected samples and proofread the manuscript. T.W.S. (Central Veterinary Research Institute, Zambia) prepared the samples. M.M. (Southern African Development Community Secretariat, Botswana) proofread the manuscript and designed the project. M.M.R. (Sokoine University of Agriculture) designed the project. P.N.W. (Sokoine University of Agriculture) offered mentorship and helped to prepare the manuscript.

\section{References}

Callahan, J.D., Brown, F. \& Osorio, F.A., 2002, 'Use of a portable real-time reverse transcriptase-polymerase chain reaction assay for rapid detection of foot-andmouth disease virus', Journal of the American Veterinary Medical Association mouth disease virus', Journal of the American Veterinary Medical
220(11),1636-1642. http://dx.doi.org/10.2460/javma.2002.220.1636

Ferris, N.P., King, D.P., Reid, S.M., Hutchings, G.H., Shawa, A.E., Paton, D.J et al. 2006, 'Foot-and-mouth disease virus: A first inter-laboratory comparison trial to 117, 130-140. http://dx.doi.org/10.1016/j.vetmic.2006.06.001

Hunter, P., 1997, 'Vaccination as a means of control of foot and mouth disease in SubSaharan Africa', Vaccine 16(2/3), 261-264.

Knowles, N., 2010, 'FAO World Reference Laboratory for FMD', Molecular epidemiology reports, viewed on 22 June 2011, from http://www.wrlfmd.org/fmd genotyping/ africa/zam.htm

Kitching, R.P. \& Donaldson A.I., 1987, 'Collection and transportation of specimens for vesicular virus investigation', Revise Science Techniques Office International Epizotics 6, 263-272.

Li-na, M., Jie, Z., Hao-tai, C., Jian-hua, Z., Yao-zhong, D. \& Yong-sheng, L., 2011, 'An overview on ELISA techniques for FMD', Virology Journal 8, 419. http://dx.doi. overview on ELISA techniques
org/10.1186/1743-422X-8-419

Longjam, N., Deb, R., Sarmah, A.K., Tayo, T., Awachat, V.B. \& Saxena, V.K., 2011, 'A Brief Review on Diagnosis of Foot-and-Mouth Disease of Livestock: Conventional to Review on Diagnosis of 'Foot-and-Mouth Disease of Livestock: Conventional to org/10.4061/2011/905768

Loth, L., Osmani, M.G., Kalam, M.A., Chakraborty, R.K., Wadsworth, J., Knowles, N.J., Hammond, J.M. \& Benigno, C., 2011, 'Molecular Characterization of FootN.J., Hammond, J.M. \& Benigno, C., 2011, 'Molecular Characterization of Foot-
and-Mouth Disease Virus: Implications for Disease Control in Bangladesh', and-Mouth Disease Virus: Implications for Disease Control in Bangladesh',
Transboundary and Emerging Diseases 58, 240-246. http://dx.doi.org/10.1111/ Transboundary and Emerging
j.1865-1682.2011.01206.x

Mweene, A.S., Pandey, G.S., Sinyangwe, P., Nambota, A., Samui, K. \& Kida, H., 1996 'Viral diseases of livestock in Zambia', Japanese Journal of Veterinary Research 44(2), 89-105.
Mwiine, F.N., Ayebazibwe, C., Olaho-Mukani, W., Alexandersen, S., Balinda, S.N., Masembe, C., et al., 2009, 'Serotype Specificity of Antibodies against Foot-and-Mouth Disease Virus in Cattle in Selected Districts in Uganda', Transboundary and Emerging Disease Virus in Cattle in Selected Districts in Uganda', Transboundary and Em
Diseases 57(5), 365-74. http://dx.doi.org/10.1111/j.1865-1682.2010.01157.x

Office International des Epizooties (OIE), 2010, 'Foot-and-mouth disease', in Manual of Standards for Diagnostic Tests and Vaccines for Terrestrial Animals, viewed on 10 July 2011, from www.oie.int/manual-of-diagnostic-tests-and-vaccines-forterrestrial-animals.

Overby, E. \& Zyambo, G.G.N., 1983, 'Foot and Mouth disease outbreaks in Zambia', Review Science Technical office of international epizootics 2(1), 189-197.

Perry, B.D. \& Hedger, R.S., 1984, 'History and epidemiology of foot and mouth disease in Zambia: A review', Tropical animal Health Production 16, 107-114. http://dx.doi. in Zambia: A review', Trop
org/10.1007/BF02239854

Rweyemamu, M., Roeder, P., MacKay, D., Sumption, K., Brownlie, J. \& Leforban, Y., 2008, 'Planning for the Progressive Control of Foot-and-Mouth Disease Worldwide', Transboundary and Emerging Diseases 55, $173-87$.

Thomson, G.R. \& Bastos, A.D.S., 2004, in Coetzer, J.A.W., Tustin, R.C. (eds.), 'Foot-andMouth Disease', Infectious Diseases of Livestock, 2nd edn., Oxford University Press, South Africa, pp. 1324-1365.

Thomson, G.R., Vosloo, W. \& Bastos, A.D., 2003, 'Foot and mouth disease in wildlife', Virus Research 91, 145/161.

Picado, A., Speybroeck, N., Kivaria, F., Mosha, R.M., Sumaye, R.D., Casal, J. \& Berkvens, D., 2010, 'Foot-and-Mouth Disease in Tanzania from 2001 to 2006', Transboundary and Emerging Diseases, 865-1682.

Roeder, P.L., Le Blanc, R. \& Smith, P.M., 1987, 'The detection and typing of foot-and-mouth disease virus by enzyme-linked immunosorbent assay: A sensitive, rapid and reliable technique for primary diagnosis', Research in Veterinary Science 43, 225-232.

Shaw, A. E., Reid, S.M., Ebert, K., Hutchings, G.H., Ferris, N.P. \& King, D.P., 2007, Implementation of one step real-time RT-PCR protocol for diagnosis of footand-mouth disease', Journal of Virological Methods 143, 81-85. http://dx.doi. org/10.1016/j.jviromet.2007.02.009

Vosloo, W., Bastos, A.D.S. \& Boshoff, C.I., 2006, 'Retrospective genetic analysis of SAT-1 type foot-and-mouth disease outbreaks in southern Africa', Archives of Virology 151 285-298.

Vosloo, W., Bastos, A.D.S., Sahle, M., Sangare, O. \& Dwarka, R.M., 2003, 'Virus topotypes and the role of wildlife in Foot and Mouth Disease in Africa', in Proceedings of the Southern and East African experts panel on designing successful conservation and development Interventions at the Wildlife/Livestock Interface: Implications for Wildlife, Livestock and Human Health, AHEAD (Animal Health for the Environment Wildife, Livestock and Human Health, AHEAD (Animal Health for the Environment
And Development) Forum, IUCN Vth World Parks Congress (Steven A. Osofsky) 14th and 15th September 2003, Durban, South Africa, p. 24.

Vosloo, W., Bastos, A.D., Sangare, O., Hargreaves, S.K. \& Thomson, G.R., 2002, 'Review of the status and control of foot and mouth disease in sub-Saharan Africa', Review Science Technical 21, 437-449. http://dx.doi.org/10.1007/s00705-005-0629-3

Vosloo, W. \& Thomson, G.R., 2004, 'Natural habitats in which foot-and-mouth disease viruses are maintained', in E. Domingo \& F. Sobrino (eds.), Foot-and-mouth disease Current perspectives, Horizon Bioscience, Great Britain.

Ministry of Livestock and Fisheries, 2010, Ministry of Livestock and Fisheries Annual Report, p. 22, Government Printer, Lusaka, Zambia. 